\title{
Usinagem aplicada a sementes ornamentais brasileiras: utilizando o design para tornar o setor da biojoia mais competitivo
}

\author{
Machining applied to Brazilian ornamental seeds: using design to make the biojewel sector \\ more competitive
}

\author{
Lana, Sebastiana Luiza Bragança; PhD; \\ Universidade do Estado de Minas Gerais \\ sebastiana.lana@gmail.com \\ Benatti, Lia Paletta; Mestranda; \\ Universidade do Estado de Minas Gerais \\ lia.paletta@gmail.com
}

\begin{abstract}
RESUMO
Este artigo apresenta os primeiros resultados das etapas de experimentação da pesquisa intitulada "Aperfeiçoamento das técnicas de acabamento decorativo em sementes brasileiras para a competitividade no setor do artesanato através de produtos com perfil sustentável". O presente artigo é parte da pesquisa para o mestrado do Programa de Pós-Graduação em Design da Universidade do Estado de Minas Gerais, e se insere na linha de Design, Materiais, Tecnologia e Processos. A presente pesquisa tem o objetivo de mostrar que através do trabalho com acabamentos decorativos, ou o chamado design de superfície, aplicado às sementes brasileiras comumente utilizadas para a produção de biojoias é uma ação inovadora e pode auxiliar no aumento da competitividade do setor do artesanato com sementes. Desta forma, as etapas principais do estudo que geraram inclusive em uma materioteca de sementes brasileiras foram: pesquisa bibliográfica, análise das sementes, produção de imagens, experimentação através da usinagem, avaliação dos resultados e conclusão.
\end{abstract}

Palavras-chave: Sementes ornamentais, biojoia, design de joias, usinagem.

\begin{abstract}
This paper presents the first results of the experimental stages of research for the entitled "Improvement of decorative finishing techniques in Brazilian seeds for competitiveness in the industry through the craft products with sustainable profile." This paper is part of research for the Masters of the Post-Graduate Program in Design of the University of the State Minas Gerais, and is in the line of Design, Materials, Technology and Processes. This research aims to show that by working with decorative finishes, or the so-called surface design, applied to the Brazilian seeds commonly used for the production of biojewels is an innovative action and can help to increase the competitiveness of the sector of handicraft with seeds. Thus, the main stages of the study for this paper, that even resulted into the production of an archiving of Brazilian seeds, were: references on literature, seed analysis, imaging, trial by machining, evaluation of the results and conclusion.
\end{abstract}

Key-words: Ornamental seeds, biojewel, jewel design, machining.

\section{Introdução}

Observando-se o comportamento frequente do mercado que apresenta grande abertura 
para produtos com perfil sustentável, o objetivo principal da presente pesquisa é utilizar as técnicas da joalheria para criação diferenciada de superfícies em metais e aplicá-las de maneira semelhante às sementes brasileiras que atualmente são consideradas ornamentais e desta forma utilizadas no desenvolvimento de biojoias. Assim como na joalheria criam-se acabamentos decorativos para os metais nobres como forma de diferenciação de um produto, o desenvolvimento e aplicação de novos acabamentos para sementes ornamentais pode apresentar o mesmo tipo de resultado, e se mostra um campo para ser explorado. Neste artigo, entende-se por biojoia a aplicação destas sementes na produção de acessórios de moda, como colares, pulseiras, anéis, entre outros, tanto como elementos únicos como aliadas a outros materiais, como tecidos, metais e pedras.

A proposta a ser desenvolvida tem o objetivo de trabalhar algumas das sementes mais comuns no mercado brasileiro e estudar para que seja feita uma catalogação de resultados em que sementes são tingidas e usinadas.

Segundo BECKER (2005) "mudanças em nível global, nacional e regional em sintonia indicam que a valorização do patrimônio natural amazônico é imperativo e urgente, para atender às demandas sociais e à competitividade internacional".

As sementes hoje deixaram de ser utilizadas apenas pelo artesanato local, no Brasil elas aparecem aplicadas a acessórios nos grandes desfiles de moda nacional e são exportadas para todo o mundo. Segundo BANDEIRA (2008):

\footnotetext{
"De início relacionada à história natural e à etnografia, as sementes ultrapassaram os limites dos herbários e do artesanato tradicional, atingindo uma beleza de caráter universal. Apesar da sua transfiguração de semente exótica em joia cosmopolita (...) ela conserva ainda o mistério de suas origens na sua própria textura. Não importa o quão longa ou sofisticada possa ter sido sua trajetória dos igarapés às vitrines de Paris ou Viena, ela conserva uma mística original, uma textura exótica, cujo cerne é impossível de ser destituído".
}

O artesanato possibilita expressar o domínio de uma técnica, uma tradição, trabalha com o imaginário de uma cultura específica, todos estes aspectos possibilitam ao produto artesanal uma forma genuinamente nacional.

Muitos dos produtos produzidos em massa apresentam pouca diferenciação, além da ausência de elementos regionais sendo que muitas vezes as preocupações operacionais e mercadológicas podem dificultar o trabalho orientado pelo regional. Porém o artesanato consegue se diferenciar justamente pelo valor agregado por meio da cultura local e a biojoia, além de já adequar uma matéria-prima nacional a produtos de moda em diversos tipos de mercado, pode encontrar várias possibilidades. Considerando-se as referências do local de origem do artesão como forma de diferenciação, novas técnicas de produção devem ser exploradas, desenvolvidas e aperfeiçoadas para possibilitar este tipo diferenciação. Principalmente quando é trabalhada a união da joalheria com matéria-prima natural e produção artesanal é possível conseguir um resultado único, "todos os grandes joalheiros do mundo fizeram amuletos, porém, em nosso mundo agitado e competitivo a joalheria se tornou mais pessoal e significativa do que nunca (...)" (ALUN-JONES e AYTON, 2005).

\section{Metodologia}

A etapa da pesquisa que aborda a usinagem de sementes foi trabalhada dentro do seguinte esquema apresentado abaixo:

1. Pesquisa bibliográfica: objetiva o melhor entendimento do material de estudo e das formas de atuação para a experimentação;

2. Análise das sementes: definição de uma amostragem que permita conhecer as principais sementes brasileiras disponíveis no mercado para a produção de biojoias, e a separação em grupos menores para a aplicação das técnicas de usinagem;

3. Imagens: utilização de imagens produzidas através de câmeras fotográficas e microscópio 
como forma de observar e comparar os resultados obtidos;

4. Usinagem: utilização de ferramentas como serras e lixas aplicadas a um grupo de sementes selecionadas;

5. Avaliação dos resultados da aplicação das sementes;

6. Conclusões e redação do presente artigo.

\section{Desenvolvimento}

\section{Materioteca}

Há disponível nos diversos biomas brasileiros (floresta amazônica, cerrado, mata atlântica, pantanal, etc.) uma infinidade de sementes que podem ser utilizadas para a produção de produtos artesanais. Dentre todas, há uma parte já conhecida culturalmente para aplicação em biojoias. Como esta pequena fatia das sementes que são encontradas a venda no mercado de peças para a produção de biojoias ainda é um universo muito diverso, até mesmo para se definir uma amostragem para a aplicação de testes foi necessário antes conhecer melhor o objeto de estudo.

A presente pesquisa tomou início com a construção de uma materioteca básica de sementes brasileiras onde foi possível avaliar as características e propriedades das principais sementes encontradas no mercado.

Tomou-se como base a "webmaterioteca" do Centro Universitário FEEVALE, que tem em sua estrutura física uma materioteca com foco o no design para o setor de calçados, e disponibiliza as informações sobre as amostras online.

Como o objetivo principal da pesquisa de mestrado é a publicação e divulgação dos resultados, além dos exemplares físicos das sementes fez-se necessário descrever as características para a catalogação dos resultados e tornar possível a consulta por públicos diversos.

As informações apresentadas para cada semente são:

Sobre a amostra

- Nome Popular: como são chamadas nos pontos de venda;

- Nome científico;

- English common names: nomes comuns em inglês;

- Fornecedor da amostra;

- Código da materioteca.

Além das informações acima, são apresentadas duas fotografias em alta resolução, a primeira com apenas uma semente e a segunda com um par ou conjunto de sementes. Esta seção da materioteca (figura 01) consta ainda com mais duas imagens detalhadas produzidas através do MDV200, equipamento da marca Instrutherm, que consiste em um microscópio varifocal com câmera CCD e LCD.

A utilização deste equipamento foi feito em parceria com o Centro de Estudos em Design da Madeira (CEMA) da Escola de Design da Universidade do Estado de Minas Gerais. O CEMA é um centro de estudos que de acordo com ESCOLA DE DESIGN (2012):

“(...) dispõe várias linhas de pesquisa com o objetivo de produzir e difundir novos conhecimentos e inovações tecnológicas que se relacionam às áreas de Biomecânica e meio ambiente. Equipado com Laboratório de Estudos e Laboratório de Ensaios Ergonômicos, o Centro desenvolve pesquisas visando à integração entre o ser humano e o Design de Produtos que envolvem o uso da madeira".

Figura 01: à esquerda, página da materioteca referente a amostra e à direita seção que descreve a ocorrência da semente no Brasil (imagens prévias da materioteca). 


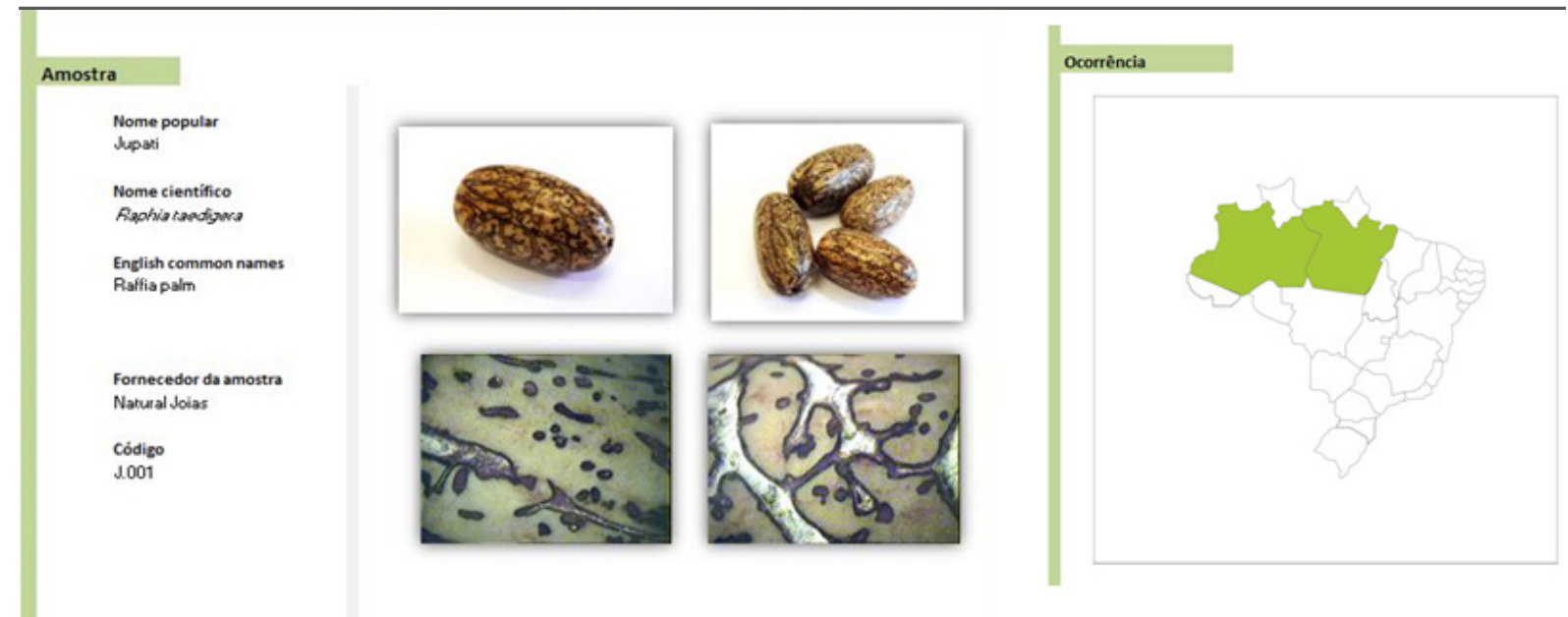

Fonte: própria (2012).

Além das informações sobre a amostra, foi descrito também a ocorrência das sementes no Brasil, como forma de mapa com os estados onde se encontram as sementes destacados.

Em relação às características, estas são comparadas através de graduação, com informações referentes à dureza, peso, rugosidade, absorção, cor e tamanho (figura 02).

Figura 02: à esquerda seção que relaciona as características das sementes. A graduação é feita a partir da comparação entre o grupo de sementes que fazem parte da materioteca. À direita, página em que constam as observações da amostra (imagens prévias da materioteca).

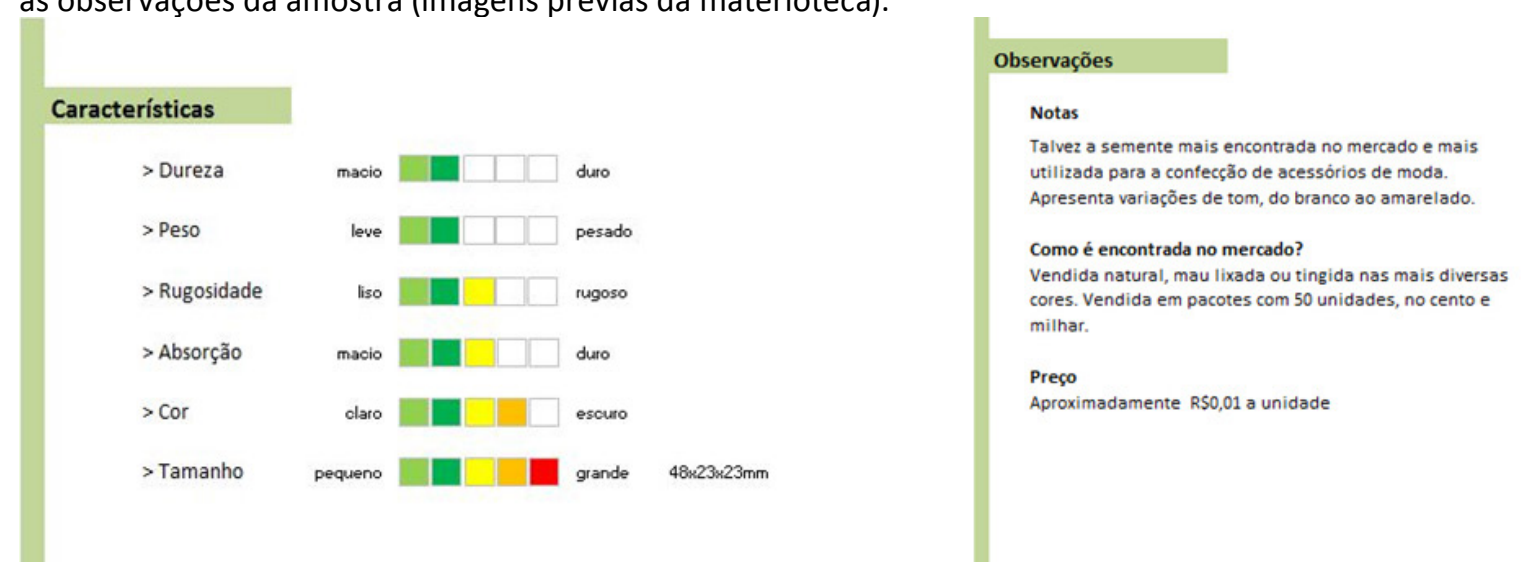

Fonte: própria (2012).

Há ainda espaço para observações pessoais relacionadas a qualquer detalhe específico do material, quando relevante para a pesquisa.

\section{Análise das sementes}

Das 17 sementes que constam, atualmente, na materioteca foi percebido uma diferença clara que as permite dividir em dois grandes grupos: o primeiro com sementes que apresentam a casca com coloração diferente do seu interior pode ser exemplificado por sementes como jatobá, dedo-de-índio, tento-carolina, olho-de-boi, olho-de-cabra, entre outras. E o segundo grupo em que esta diferenciação entre a casca e o miolo não ocorre, tem-se como exemplos o caso do açaí, jupati, jarina, bacaba, entre outras. Do ponto de vista técnico a maioria das sementes apresenta a casca com coloração e material diferenciado do seu interior. Porém, para esta pesquisa, leva-se em conta a forma como as sementes são encontradas no ponto de venda a disposição de artesãos, artistas e designers, no mercado de 
peças para a confecção de acessórios. Desta forma, grande parte das sementes já se encontra com tratamento prévio, ou seja, elas são vendidas já limpas, lixadas e furadas, sendo que, cada semente apresenta uma técnica específica que a torna ideal para a venda e o artesanato. Segundo FELIX (2007):

"O beneficiamento das sementes para o artesanato é realizado com a utilização de equipamentos que vão desde ferramentas manuais, materiais rústicos adaptados e movidos à eletricidade como polideiras, furadeiras e serra elétrica. Os artesãos geralmente efetuam o beneficiamento em oficinas, confeccionam peças e ainda disponibilizam peças e sementes beneficiadas ao mercado local e nacional".

Nesta primeira etapa de testes apresentada foram utilizadas as sementes do primeiro grupo, que apresentam a casca com a coloração diferenciada, pois foi percebido que a aplicação das ferramentas de usinagem nestas sementes proporciona um contraste interessante das cores das partes, o que permite uma grande variedade de intervenções. Segundo GOMES FILHO (2000):

"O contraste, como estratégia visual para aguçar o significado, não só excita e atrai a atenção do observador, como também é capaz de dramatizar esse significado para fazê-lo mais importante e mais dinâmico.

(...) O contraste pode ser utilizado, no nível básico de construção e decodificação do objeto, como todos os elementos básicos: linhas, tonalidades, cores, direções, contornos, movimentos, e, sobretudo, com a proporção e a escala".

\section{Aplicação de novas técnicas}

Como teste inicial, foi utilizada a semente de jatobá (Hymenaea courbaril) como mostra a figura 3. Esta semente apresenta um contraste da cor de sua casca em marrom escuro e seu interior amarelado, além de um tamanho ideal para o trabalho manual. De acordo com BANDEIRA (2008) a semente de Jatobá apresenta diversos usos:

“É utilizada em reflorestamento e na arborização de parques e jardins. A madeira é empregada na construção civil, tornearia e móveis. A polpa dos frutos contém uma farinha rica em cálcio e magnésio, sendo usada como alimento para a fauna e para o homem. O fruto e a semente são utilizados no artesanato, para confecção de móbiles, colares, brincos e pulseiras. 0 tronco possui uma resina (...) empregada na indústria de vernizes. Sua casca fornece corante amarelo (...)".

Figura 03: sementes de Jatobá.

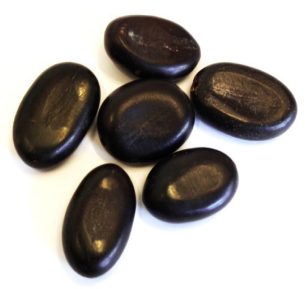

Fonte: própria (2012).

\section{Testes}

A primeira fase dos testes foi feita com uma micro retífica cujas ferramentas são intercambiáveis. Muito utilizados na joalheria, existem diversos tipos de motores para a mesa de trabalho, com diversos acessórios e cortadores acopláveis. As fresas de diamante são encontradas em forma de cone, discos, de forma redonda ou paralela, e estando afiados podem cortar adequadamente qualquer área. Para um corte redondo pequeno, médio e largo, existem fresas com formato de esfera. O motor é também uma ferramenta excelente para limpar e polir áreas pequenas (MCGRATH, 2007). 


\section{Lixa circular}

Uma lixa circular com 10 milímetros de diâmetro foi utilizada conforme se apresenta na figura 03. Posicionando contra as extremidades das sementes foi possível criar superfícies côncavas, e se aplicada ao redor da semente inicialmente consegue-se um desgaste da casca e mais profundamente é possível deixar visível três camadas de cor.

Figura 03: ferramenta, forma de aplicação e resultado do uso da lixa circular.

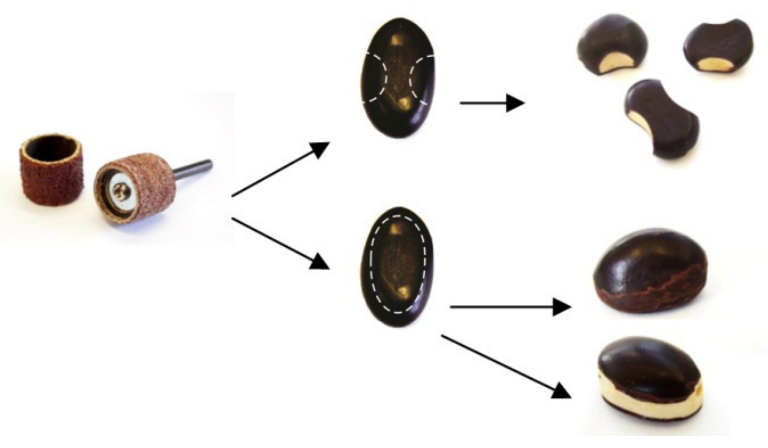

Fonte: própria (2012).

A aplicação da lixa ao redor da semente de jatobá cria um resultado interessante, porém deve ser observada com atenção no momento de aplicar em outras sementes. Foi observado em sementes como o dedo-de-índio e o olho-de-boi, que o miolo da semente se desprende facilmente da casca com este tipo de usinagem. Um dos motivos pelos quais ocorre este fato pode ser observado através das imagens produzidas por microscópio comparando a semente de jatobá e a semente dedo-de-índio.

Figura 04: Detalhe da casca da semente de jatobá.
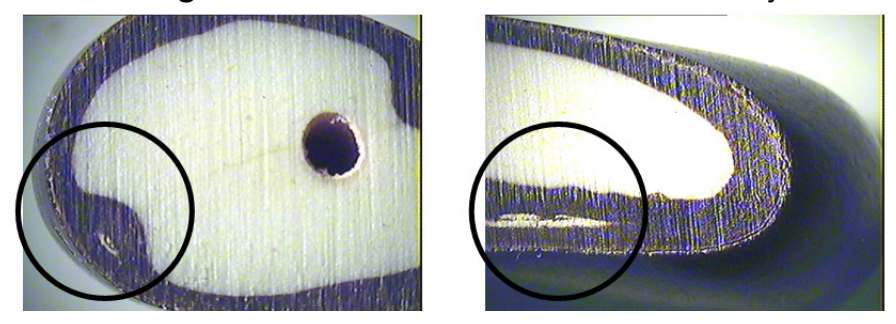

Fonte: própria (2012).

Através de cortes na semente de jatobá em sentidos transversais (figura 04) é possível observar que em diferentes pontos da semente o miolo se "entrelaça" com a casca. Desta forma é possível fazer a retirada do material da casca em diversos pontos da semente e mesmo assim o material restante não irá se desprender do seu interior.

Ao mesmo tempo, se compararmos com corte feito nas sementes dedo-de-índio (Parkia multijuga) e olho-de-boi (Dioclea SP) na figura 05, é possível ver que a separação entre casca e interior é muito mais nítida e não há o mesmo tipo de "entrelaçamento".

Figura 5: contato entre casca e interior. À esquerda corte feito em semente dedo-de-índio e à direita corte feito em semente olho-de-boi.
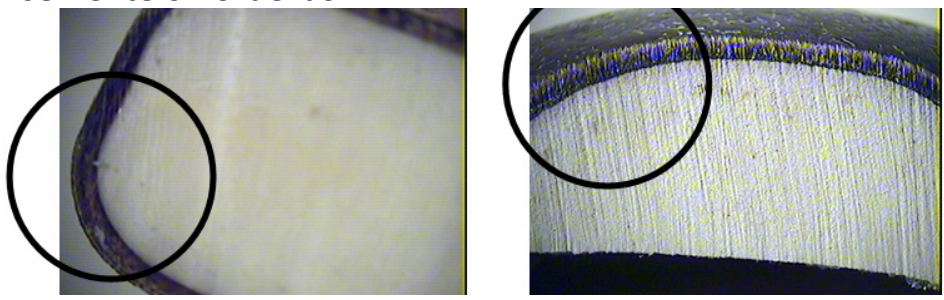

Fonte: própria (2012). 


\section{Escariador}

Um escariador com diâmetro de 3 milímetros (figura 06) foi utilizado com o objetivo de criar textura circulares, que podem ser aplicadas de forma aleatória ou ordenada, deixando o interior da semente visível apenas em pontos específicos. Esta repetição de elementos circulares na semente cria uma relação de proximidade, que de acordo com GOMES FILHO (2000) são:

"Elementos ópticos próximos uns dos outros tendem a ser vistos juntos e, por conseguinte, a constituírem um todo ou unidade dentro do todo. Em condições iguais, os estímulos mais próximos entre si, seja por forma, cor, tamanho, textura, brilho, peso, direção e outros, terão maior tendência a serem agrupados e a constituírem unidades".

Figura 06: ferramenta, forma de aplicação e resultado do uso do escariador.
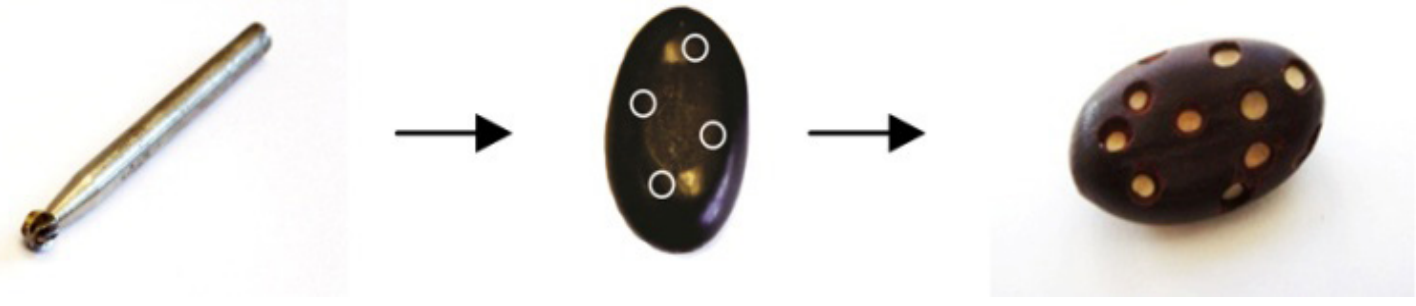

Fonte: própria (2012).

A aplicação de ferramentas como o escariador e a broca (figura 09) deve ser feitas de maneira firme e pontual. A camada superior da casca das sementes é muitas vezes quebradiça e deslizes da ferramenta criam imperfeições que podem não ser interessantes para a aparência final da biojoia (figura 07).

Figura 07: detalhe do defeito causado pela quebra da superfície da semente com a utilização

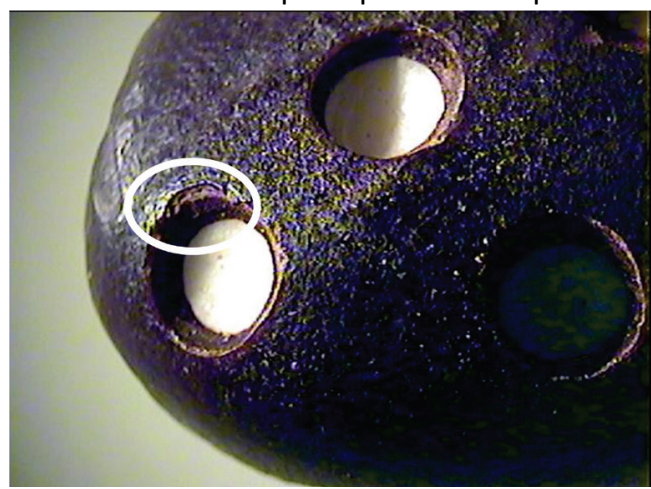

Fonte: própria (2012).

Este tipo de defeito não é apenas encontrado em trabalhos pontuais de artesãos. Pequenos defeitos na furação são facilmente encontrados em sementes vendidas no atacado no mercado, uma vez que a maioria das sementes já é vendida com o furo principal especialmente para o trabalho artesanal.

Isto ocorre não apenas pela falta de cuidado do profissional responsável pelo beneficiamento, mas também devido às dimensões muito pequenas das sementes. Muitas vezes o ferramental não está adequado ao tipo de trabalho (com mais potência do que o necessário) este tipo de erro acaba sendo comum. Desta forma, uma vez que as sementes são comumente vendidas em grandes quantidades, estes pequenos detalhes são percebidos apenas na hora da montagem da biojoia.

Figura 08: Exemplos de defeitos ocasionados pela furação em sementes encontradas no 
mercado. Da esquerda para a direita: tento-carolina (Adenanthera pavonina), feijão beiçudo (Mucuna $s p)$ e morototó (Didymopanax morototoni).

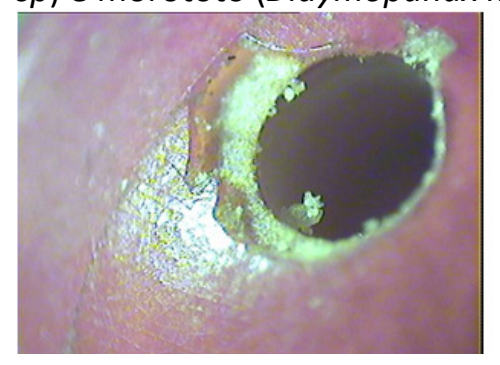

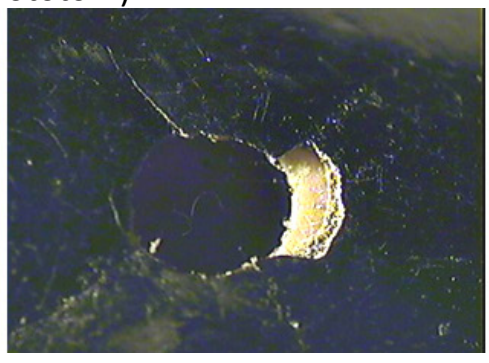

Fonte: própria (2012).

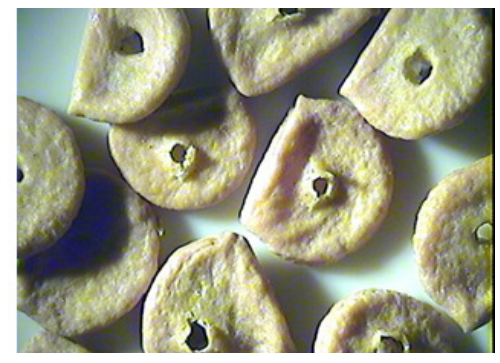

\section{Broca}

Foi utilizada uma broca com 3 milímetros de diâmetro, e a sua forma de aplicação pode ser planejada da mesma forma que o escariador, pois nada mais é do que uma interferência circular semente, com a diferença de criar um furo, tanto passante como até a metade do objeto. Este tipo de usinagem pode ser utilizado como textura de forma singular, ou utilizada para se traçar elementos de união de peças, como os fios de nylon ou arames de forma diferenciada e inusitada.

Figura 09: ferramenta, forma de aplicação e resultado do uso da broca.

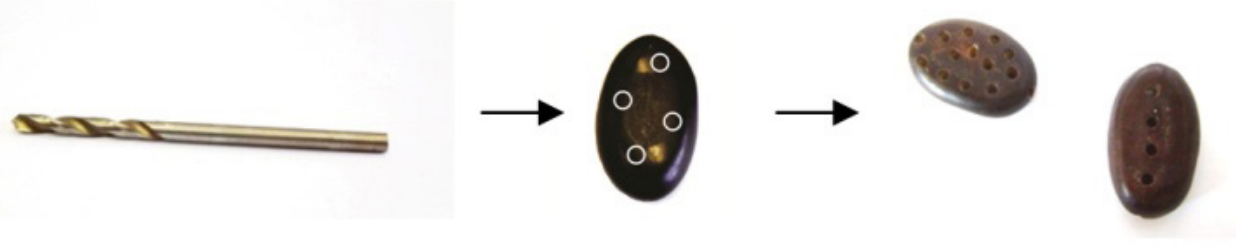

Fonte: própria (2012).

\section{Disco de corte}

O disco de corte utilizado tem espessura de 1 milímetro, feito em fibra de vidro, pode ser utilizado para criar um padrão de cortes na peça, seja aleatório ou ordenado, assim como seu uso pode ser aplicado para fatiar a semente de acordo com a figura 10.

Figura 10: ferramenta, forma de aplicação e resultado do uso do disco de corte.

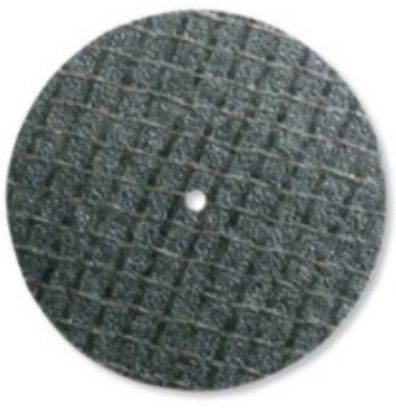

Lixa de bancada

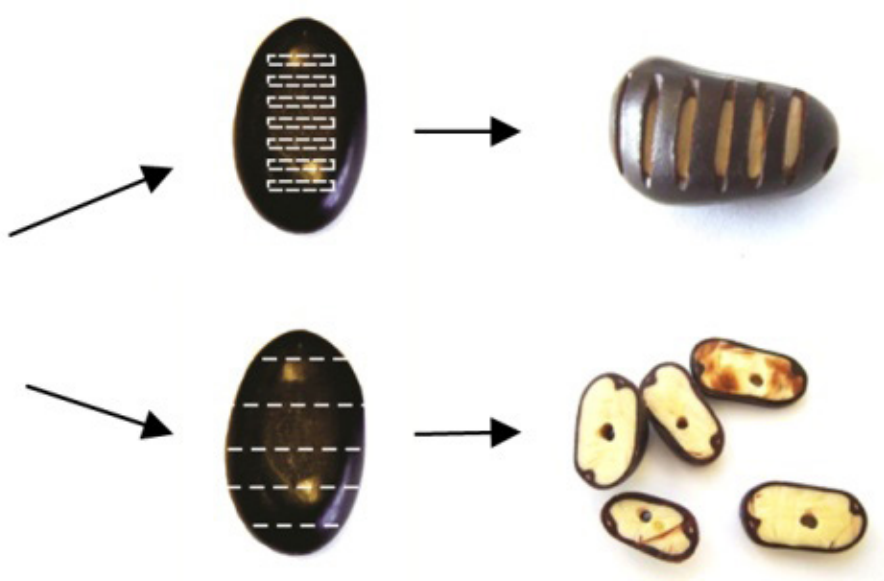

Fonte: própria (2012). 
Foi testada também a utilização de maquinário da oficina de madeira da Escola de Design da Universidade do Estado de Minas Gerais. A lixa de bancada (figura 11) permite alcançar um resultado também interessante com as sementes de jatobá, porém de forma mais homogenia e com maior rapidez. Apesar de não permitir um manejo fino, foi observado que lixando as laterais das sementes, tanto no sentido vertical quanto horizontal é possível obter um resultado diferenciado e ainda permitir a produção em maior escala.

Figura 11: ferramenta, forma de aplicação e resultado do uso da lixa de bancada.

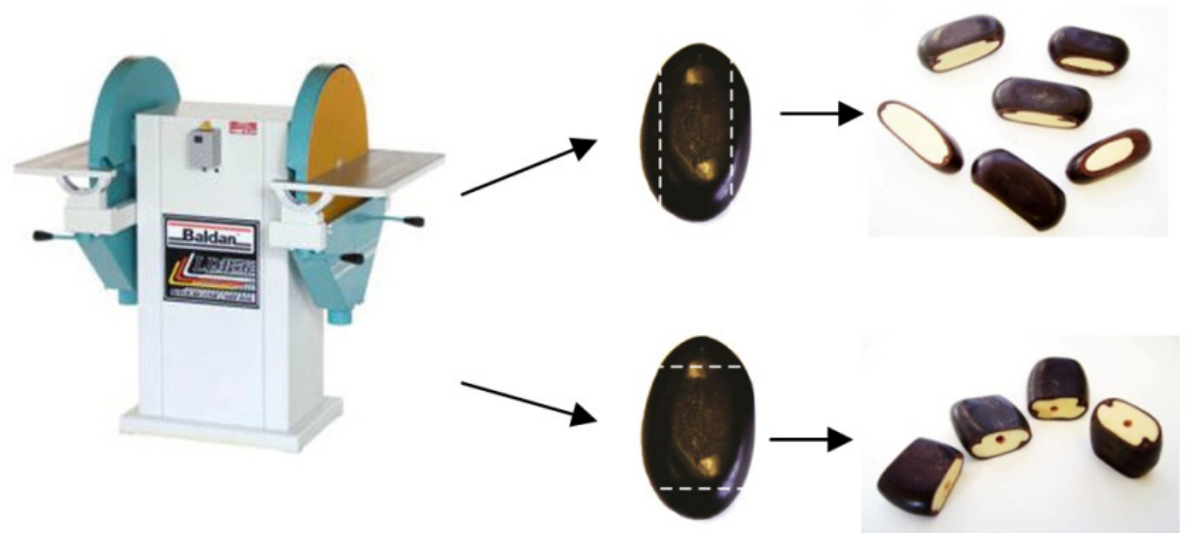

Fonte: própria (2012).

\section{Resultados}

O estudo apresenta dois resultados principais. Inicialmente a construção da materioteca, que permite uma prévia observação das principais propriedades das sementes facilitando o planejamento e escolha da aplicação das ferramentas ideias para a produção dos diferentes acabamentos. Planejase ao final da pesquisa publicar esta materioteca para divulgar as informações adquiridas ao público visado.

Em segundo lugar, como forma de aplicar os novos acabamentos nas sementes e validar o conhecimento gerado foram desenvolvidos protótipos de colares (figura 12) como estratégia para comprovar a possível utilização dos testes.

Figura 12: protótipos produzidos a partir dos acabamentos decorativos desenvolvidos. A esquerda colar com sementes de jatobá com utilização da lixa circular e a direita detalhe da aplicação do disco de corte na semente dedo-de-índio.
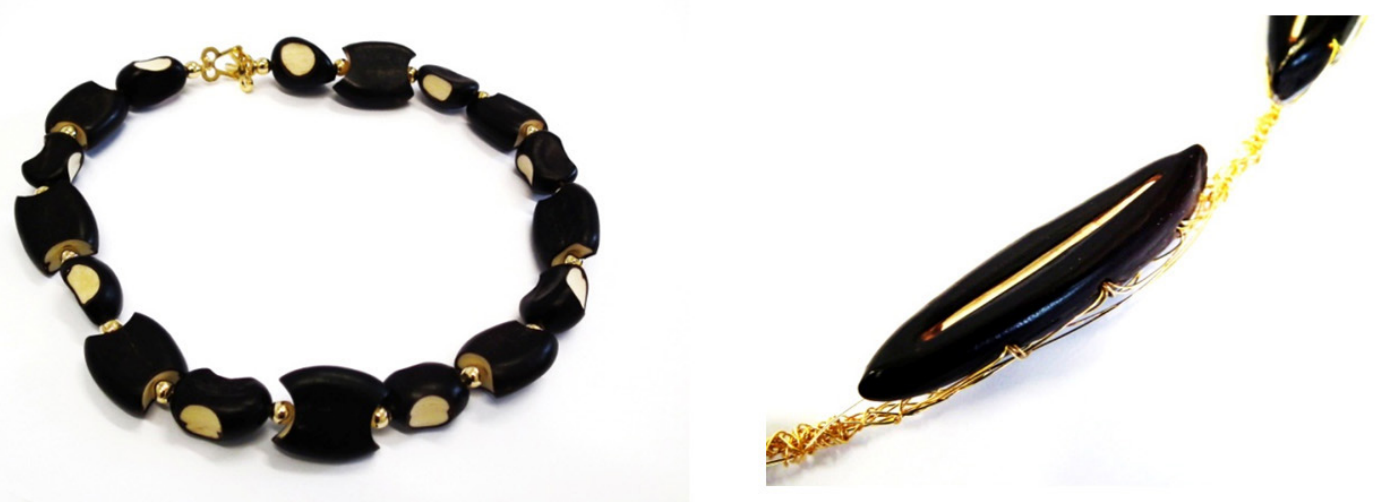

Fonte: própria (2012).

Acredita-se que este tipo de intervenção em sementes brasileiras pode tornar este segmento 
do artesanato mais competitivo, com produtos diferenciados e inovadores que possam trazer novas formas de apresentar as raízes culturais de sua localidade. De acordo com SEBRAE (2004): “(...) entre as cadeias produtivas vocacionadas do Brasil, o artesanato tem elevado potencial de ocupação e geração de renda em todos os Estados, posicionando-se como um dos eixos estratégicos de valorização do desenvolvimento dos territórios".

Foi possível observar também que a utilização de sementes aplicadas aos acessórios permite que o setor da joalheria se aproxime um pouco mais ao ritmo de atualização da moda, que aceita mistura de materiais alternativos, de origens diversas.

Outro fator que auxilia na maior aceitação do uso de sementes ornamentais é a consciência ambiental que vem se ampliando nos últimos anos. Os consumidores estão cada vez mais conscientes e buscam produtos que sejam sustentáveis, que é uma das vertentes da biojoia.

\section{Conclusões}

Foi possível observar quais ferramentas apresentam um resultado relevante para a aplicação em biojoias. As aplicações não ficam limitadas as apresentadas neste artigo, na verdade é simples perceber que as formas de se modificar a superfície de uma semente são infinitas e o resultado destes recursos aplicados a produtos vai depender também da criatividade e habilidade do artesão. Frente ao artesanato, o objetivo da presente pesquisa é disponibilizar novas técnicas de produção como forma de ajudar a incrementar o trabalho, esperando-se que em cima deste novo leque de possibilidades o artesão possa inserir todo o seu repertório visual e cultural.

A metodologia se mostrou válida para utilização e aplicação das técnicas em outras sementes, mostrando ser possível a construção de um manual, com uma quantidade maior de sementes e técnicas, com o objetivo de auxiliar artesãos, artistas, designers entre outros profissionais a desenvolverem novos produtos (acessórios de moda ou não) com as sementes ornamentais brasileiras, uma matériaprima com perfil sustentável, de ampla oferta em território nacional e preço acessível para os diversos tipos de profissionais.

\section{Referências}

ALUN-JONES, Deborah e AYTON, Jonh. Charming: the magic of charm jewelry. UK: Thames et Hudson, 2005.

BANDEIRA, Julio. Sementes ornamentais do Brasil. Rio de Janeiro: Reler, 2008.

BECKER, Bertha K. Amazônia: nova geografia, nova política regional e nova escala de ação. Amazônia Sustentável: desenvolvimento sustentável entre políticas públicas, estratégias inovadoras e experiências locais. Rio de Janeiro: Garamond; Tübinger, Alemanha: Geographischen Instituts de Universität Tübingen, 2005.

ESCOLA DE DESIGN. Centro de Estudos em design da Madeira. Disponível em: <http://www.ed.uemg. br/atuacoes/centros/design-madeira> Acesso em: 26/04/2012

FEEVALE. Materioteca. Disponível em: <http://materioteca.feevale.br:8080/webmaterioteca/externo/index.jsp> Acesso em: 10/04/2012.

FELIX, Ana Angélica Alves. Identificação e desenvolvimento de técnica alternativa de controle de fungos em sementes utilizadas no artesanato. Universidade de Brasília, 2007. Disponível em: <http:// repositorio.bce.unb.br/bitstream/10482/3322/1/2007_AnaAngelicaAlvesFelix.PDF> Acesso em: 15/03/2012.

GOMES FILHO, João. Gestalt do objeto: sistema de leitura visual da forma. São Paulo: Escrituras Editora, 2000. 
Usinagem aplicada a sementes ornamentais brasileiras: utilizando o design ... da biojoia mais competitivo SEBRAE. Programa Sebrae de Artesanato. Termo de referência: março de 2004. 